\title{
MEMS Biomedical Sensor for Gait Analysis
}

\author{
Yufridin Wahab and Norantanum Abu Bakar \\ University Malaysia Perlis \\ Malaysia
}

\section{Introduction}

Gait analysis is the study of lower limb movement patterns and involves the identification of gait events and the measurements of kinetics and kinematics parameters. These include for example, toe-off, landing, stance, swing, displacement, speed, acceleration, force, pressure and the pressure-time-integral. Gait analysis is a very important procedure in assessing and improving many quality of life indicators. In sports, gait analysis can be used to improve athlete's performance and injury prevention. For patients, such as those suffering from diabetes, gait analysis can be used to screen for development of foot ulceration thus preventing them. In term of gait stability, gait analysis is proven to be very helpful in assessing and improving balance among the elderly, patients with diabetes or peripheral neuropathy and many other sicknesses. Gait analysis is also widely used in rehabilitation.

The occurrence of fall is becoming more of a significant health threat recently. This is due to the fact that the worldwide phenomenon of growing population of the elderly is continuously observed in many developed and developing countries. It is estimated that the world's elderly citizen will reach 2 billion in 2050 from current figure of 670 million. To make matters worse, the total number of the world's diabetic sufferers is increasing from 171 million in 2000 to 366 million in 2030, with an obvious trend of surging proportion for the above 65 years group.

In order to further understand the situation that leads to the health hazard, many research groups around the world are seriously looking into the matter. Recently, it is reported that foot plantar pressure can be used to asses gait stability and risk of fall. In addition, foot clearance above ground/floor during gait is also reported to be related to the occurrence of fall among the elderly. This is especially true when the foot is swaying on the air, or also called swing phase. Notably, pressure is measured when the foot is already touching the ground, which is known as stance phase, while clearance is measured during mid-swing to heel strike. If both pressure and clearance parameters of gait analysis are used together in an integrated manner, a better way of fall prediction and prevention can be produced.

In addition to assessing balance, the measurement of foot plantar pressure and foot clearance are also useful in many other gait assessments. This foot pressure measurement has wide applications, for example in screening for high risk diabetic foot ulceration, design of orthotics for diabetes mellitus and peripheral neuropathy, footwear design, sports injury prevention in athletes, study of the development of gait among the children plus many more. It also can be used to identify gait events such as heel strike, toe off, the timing of swing, stance, stride, the double support phase and also cadence. If stride length is known, 
the horizontal speed and acceleration can also be determined. On the other hand, the foot clearance measurement can also be useful in determining the vertical component of gait kinematics such as maximum vertical displacement, vertical velocity and its acceleration.

At current, the health system is still lacking. While the ratio of medical professional to patients is reducing, such measurements are still mostly conducted in exclusive research facilities, rehabilitation laboratories or hospitals. For example, the use of gait mats, force sensing platforms, motion analysis systems with efficient computer processing and ultrasonic ranging system are used for indoor analysis. Despite their efficiency and reliability, these state-of-the-art measurement systems are still using the bulky old fashioned technology. Considering the global trend of increasing elderly and diabetic population, a major paradigm shift is therefore highly required. As a solution, the advances in the instrumentation technology should be explored and used to its fullest capability. The aim is to enable the measurement to be performed in the patient's real environment with the revolutionary e-health connectivity and supporting pervasive healthcare concept.

While e-health system demands internet application for better management and implementation of healthcare provision, pervasive healthcare promotes wireless interconnection between monitoring devices. In this case, sensors that are part of body sensor network can be used. These sensors should not interfere with the actual movement itself so that the readings are representative of the actual tasks performed. This demands that the devices be small, lightweight and easily attached to the shoes or feet. One possible way of satisfying such exclusive demands is, of course, through the application of the fast developing micro-electro-mechanical system (MEMS) technology. This relatively new but promising instrumentation technology provides a great opportunity to further advance the intended gait measurement system.

This technology is proven to be capable of shrinking the device size, integrating sensors and actuators with their processing and controlling circuitry and lowering the power consumption of the overall system. The fusion of its technology is now covering wide applications across a multitude of disciplines from medical to military and spaces from invitro of human body organs to the infinity of aerospace. The great achievement has been due to cheap and easy integration of microelectronic signal processing circuits and MEMS technologies. Thus, the potential of these technologies should be explored in the design of newer generation of gait analysis instruments to ensure greater progress of the gait analysis application with significant impact to society. Therefore, in this thesis, the exploration and realization of micro-sensors for the measurement of gait parameters using MEMS technology is explained.

As roughly mentioned in the previous section, the current status of the development of untethered in-shoe gait stability measurement devices is still lacking behind the reality of technology achievement. In this subsection, the motivation for this research is described. Specifically, with respect to their measurand, the current devices are not fully optimized in many aspects.

Foot Clearance:

- Not suitable for real world or outdoor measurement.

- Not cost effective

- Not enabling efficient signal processing

- Not fully integratable for better reliability and long lasting use 


\section{Foot Plantar Pressure:}

- Not providing the required pressure range for diabetic related application

- Not supporting efficient signal processing

- Exhibits hysteresis and other weaknesses.

Most interestingly, despite the proven track records, there is no reported innovation that targets gait analysis parameters of clearance and plantar pressure concurrently based on MEMS as yet.

\section{Trends in human motion measurement}

Gait is simply defined as a style of walking (Curran, 2005). Gait analysis is the study of lower limb movement patterns and involves the measurements of kinetics and kinematics parameters. These include, for example gait events and phases such as toe-off, landing, stance, swing, double support, and kinematics such as foot displacement, speed, acceleration, and kinetics such as force, pressure and the pressure-time-integral (Rodgers, 1988). The understanding of normal gait principles is the basis for understanding the pathologic and compensatory gait deficits. Normal gait for human being is bipedal in nature that distinguishes human from other primates but is often taken for granted until something goes wrong (Curran, 2005). It is achieved by use of the lower limbs that comprise of foot as one of the key parts. The foot is a complex structure that is made of 26 bones, 33 joints and more than 300 soft-tissue structures (Curran, 2005). As the terminal structure in the human kinetic chain, it performs the pivotal roles of dissipator for compressive, tensile and shear forces while performing rotational motions during stance. In other words, from a podiatrics point of view, foot functions as a shock absorber, a mobile adapter and finally a rigid lever (Curran, 2005). Nowadays, the need for the measurement of human motion parameters is getting higher due to the increase in the number of fields requiring it, especially numerous medical specializations (Simon, 2004), activity of daily living (ADL) assesment and sports (Billing et al.,2006; Aminian \& Najafi, 2004). In medical field, the use of gait analysis encompasses the tests for central nervous disorders, locomotor disorders, rheumatology, orthopedics, endocrinology and neurology (Simon, 2004). At present, the measurement is mostly performed in specialized facilities such as hospital or laboratories (Best \& Begg, 2006). These facilities require very high setting up cost (Simon, 2004). Despite the high cost, it is argued that the performed measurement is not accurate or a true representative of the actual daily activities of the subject as it is claimed to only gauge a person's potential walking ability at a given time (Simon, 2004). In fact, the facilities also limit the space usable for the measurement. It is claimed that the most inconvenient aspects of these systems is the fact that the subject must walk in a closed and restrained space (Aminian \& Najafi, 2004). The expanding use of gait analysis is catalyzed by the fact that it is able to evaluate walking "out-of-the lab" where most of the daily living activities are performed (Simon, 2004). As an example, it is reported that the locations where falls occur are $77 \%$ outside of the house (Berg et al., 1997). Even though the recent instruments does not measure the gait in real living condition, the trends is moving towards that direction. In addition to their competitive price, user friendliness, miniaturized for portability, capability of efficiently recording and processing larger number of parameters in less time and space are among the required traits of such devices (Simon, 2004). Obviously, these 'dream' system can only be materialized by adoption of the already practically proven microelectronics and micro-electro-mechanical system technologies. 
These technologies are said to bring over a number of significant improvements into biomedical instrumentation realization which includes miniaturization, low power consumption, full integration of system and also low cost of production (Bryzek et al., 2006; Jovanov et al., 2005; Hierold,2003). Miniaturization is a great advantage as it means the devices or systems should require only small volume of space. With low power consumption, only small batteries might be needed as power supply, or maybe even energy scavenging can be enough to power them up, if not a combination of them. As full system integration on single silicon chip is also possible, the signal processing and computation can be performed on the same silicon piece with greatly improved overall system performance. Most interestingly, the low per-unit cost is what business and consumers are looking for in every product and have been an undeniable trend (Grace, 1991). In addition, technologically, it also offers numerous materials that not only excellent mechanically for sensing and actuation (Bryzek et al., 2006), they are also biologically compatible (Kotzar et al., 2002). Undoubtedly, these MEMS based devices are the promising tools for outdoor ambulatory measurement and monitoring (Aminian \& Najafi, 2004). More interestingly, biomedical application is considered as one of the key new frontiers of MEMS based device development in the future with the worth of billions of dollars (Ko, 2007; Kotzar et al., 2002). In short, with the integration of elegant engineering, advanced instrumentation technology and continuous development in computing propels the art and science of human movement analysis beyond its basic description towards a more prominent role in surgery decision making, orthosis design, rehabilitation, ergonomics and sports (Curran, 2005).

\section{Foot pressure measurement: an overview}

Fig. 1 depicts foot plantar pressure pattern during gait. The foot is the key limb in human movement. Without foot, a person's mobility is significantly reduced. As a result, the activities of daily living are limited and quality of life is dropped. One way of determining the foot health is by examining the foot plantar pressure. For example, foot ulceration due to diabetes related excessive foot plantar pressure is estimated to cause over $\$ 1$ billion per year worth of medical expenses in the United States alone (Mackey \& Davis, 2006). Diabetes is now considered an epidemic and the number of patients is expected to increase from 171 million in 2000 to 366 million in 2030 (Wild et al., 2004). It is therefore critical to ensure the availability of an accurate and efficient technique of measuring this type of pressure.

In fact, the interface pressure between foot plantar surface and shoe soles is among the key parameters frequently measured in biomechanical research. This parameter is widely used in various applications, for example, screening for high risk diabetic foot ulceration, design of orthotics for pressure redistribution of diabetes mellitus and peripheral neuropathy patients, design of footwear (Mueller,1999), improvement of balance (Santarmou et al.,2006; Bamberg et al., 2006), sports injury prevention in athletes (Gefen, 2002).

Traditionally, the foot plantar pressure measurement is performed in the specialized settings such as laboratories, hospitals or other clinical premises (Best \& Begg, 2006). This includes various gait analysis systems such as foot plantar pressure platforms and foot plantar pressure mats. Due to their sizes and the number of equipments required, these measurement systems require specialized settings.

As the depicted pressure measuring systems measure barefoot pressure, the results are obviously not representing real dynamics of foot-shoe interactions. Due to these two 


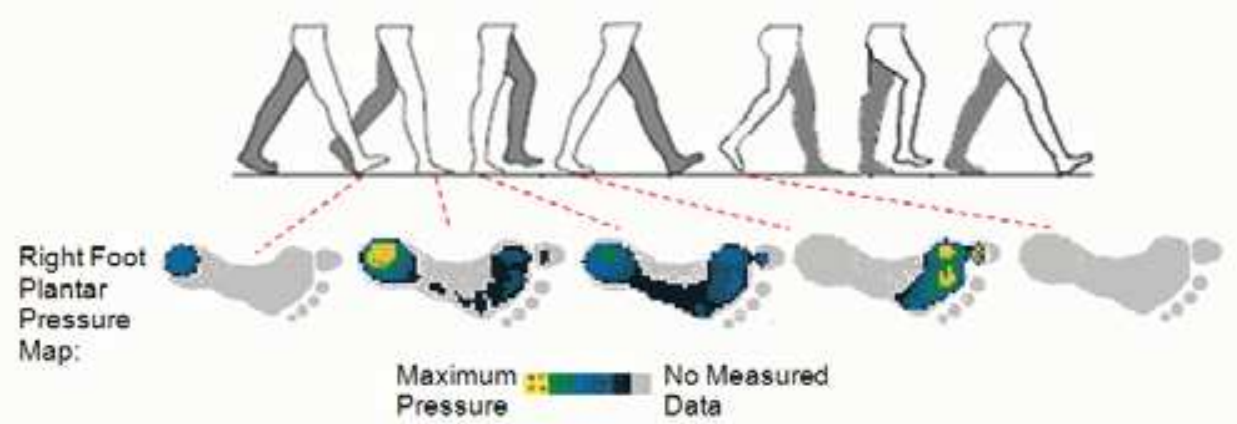

Fig. 1. Foot plantar pressure changes during gait. The foot plantar pressure during stance phase can be measured using many methods and tools.

obvious limitations, a more natural way of measuring pressure is highly required. For that reason, in-shoe pressure measurement devices are more suitable for use in natural living environment.

\subsection{In-shoe pressure sensing}

Nowadays, a number of foot-shoe pressure sensors are available in the market and many are mentioned in (Urry, 1999). These sensors are made of many different types of material, using different types of manufacturing technologies, made in different sizes, characterized by unique specifications and are operated based on various measurement techniques.

The materials include flexible polymeric layers, dielectrics and also electrical conductors. Some materials used in the sensor development limit the sensor's performance thus creating many issues such as hysteresis, repeatability, accuracy and creep as highlighted in (Lee et al.,2001; Wheeler et al., 2006). Slow response time is among the highlighted weaknesses too (Wheeler et al., 2006). In short, there are obviously many limitations of the currently available sensors in the market as discussed in detail and compiled in the literature (Hsiao, Guan \& Weatherly, 2002). Many of the sensors are made as arrays of similarly sized sensor elements. Size of individual sensor affects the efficiency of the measurement system (Urry, 1999). Basically, there are two categories of in-shoe sensors available, the research ones and the commercial ones. Examples of sensor integrated shoes are shown in Fig. 2 which include GaitShoe (Morris, 2004; Bamberg et al, 2008), Smartshoe (Kong \& Tomizuka, 2008) and another instrumented (Liedtke et al., 2007). There are also other related works (Abu-Faraj et al., 1997; Tanwar, Nguyen \& Stergiou, 2007). Fig. 3 presents some of the available instrumented insoles.

In terms of measurement technique, commonly used techniques are resistive, capacitive, ink-based and others. Each of the techniques offers unique sensitivity and other signal properties. The sensors that are made of polymer or elastomer exhibits some limitations. The resulting issues include repeatability, hysteresis, creep and non-linearity of the sensor output (Lee et al., 2001). In addition to the above weaknesses, some sensors have a relatively large sensor size that may significantly underestimate the pressure, if the arguments in (Urry, 1999) is considered. In fact, this view is supported by another report too (Sarah, Carol \& Sharon, 1999). 


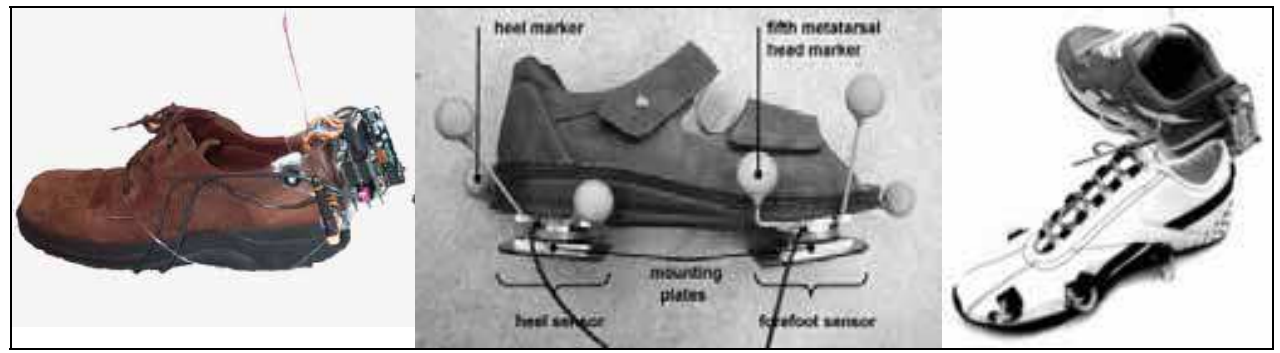

Fig. 2. (Left) The Gaitshoe proposed in MIT (Morris, 2004; Bamberg et al.,2008), (Middle) The instrumented shoe for Ground Reaction Forces determination (Liedtke et al., 2007) and (Right) SmartShoe (Kong \& Tomizuka, 2008).

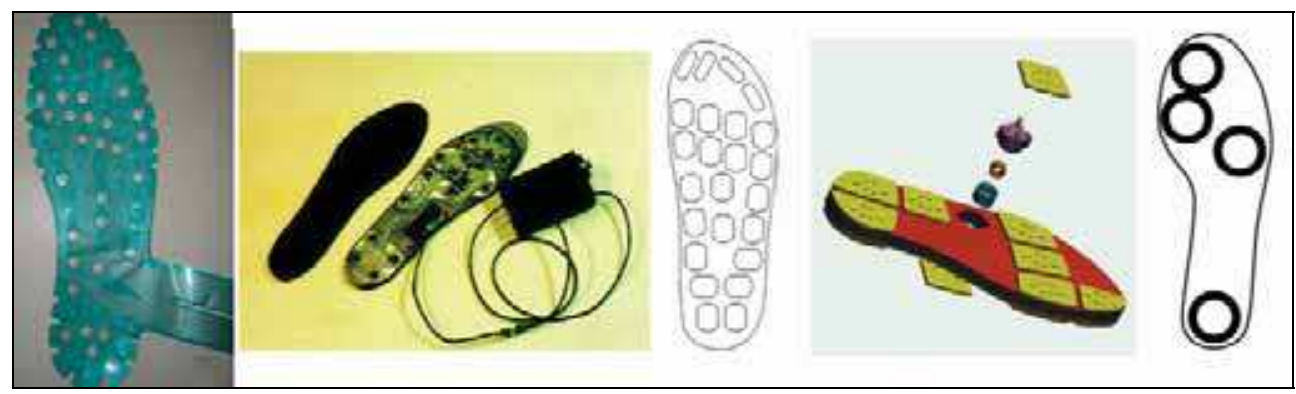

Fig. 3. (Far Left) Bio-foot $₫$ insole with 64 piezoelectric pressure sensors (Martinez-Nova et al., 2007), (Middle Left) the SIMS insole with 32 pressure sensors (Zhang et al., 2004), (Middle) the Parotec insole layout (Chesnin, Selby-Silverstein \& Besser, 2000), (Middle Right) the instrumented shoe sole (Faivre et al., 2004) and (Far Right) the SmartShoe sole (Kong \& Tomizuka, 2008).

\subsection{The application requirement}

In performing any measurement, the measuring device must be optimized for that specific application, or else, the observed readings might possibly not accurate. Therefore, a very careful and detail analysis of the specific application requirement must be thoroughly considered before any measurement is performed. Any devices that are to be used in gait analysis must fulfill the requirements such as those explained in detail in (Lee et al.,2001; Urry,1999; Morris, 2004; Bamberg et al.,2008). The required key specifications for a pressure sensor in terms of sensor performance include linearity (linear), hysteresis (low), operating frequency (at least $200 \mathrm{~Hz}$ ), creep and repeatability (no creep or deformation over repetitive or high cyclic loads), temperature sensitivity $\left(20^{\circ} \mathrm{C}\right.$ to $\left.37{ }^{\circ} \mathrm{C}\right)$, sensing size, pressure range (every $31.2 \mathrm{~mm}^{2}$ foot plantar area is close to $2.3 \mathrm{MPa}$ ), sensing area of the sensor and its placement (micro sized sensors as a dense array sensor).

\subsubsection{In-shoe implementation requirement}

Nowadays, real-time and in-situ measurement of natural parameters is becoming an unavoidable trend. To catch-up with the fast changing and very demanding trend, also, as gait analysis is about measurement of uninterrupted real parameters, it is very important 
that the measurement is performed in the real environment. In fact, the effect of daily activities on our health is clearly understood (Urry, 1999). This means the sensor should be very mobile, un-tethered, can be placed in the shoe sole and also can measure effectively in the targeted environment. The detailed requirements are very mobile, limited cabling, shoe placement and also low cost.

\subsubsection{Diabetic requirement}

In diabetic application, no reports highlight any required additional features other than pressure range. For this reason, the maximum pressure measurable is the only key determining factor. Pressure readings as high as $1900 \mathrm{kPa}$ is reported in the literature (Cavanagh, Ulbrecht \& Caputo, 2000). This is obviously a very demanding requirement, as compared to the maximum pressure as obtained in normal people. The pressure ranges of the currently available sensors are very limited. As an example, most of the diabetic sufferers are off the scale as the upper measuring limit of the Emed SF device is approximately $1250 \mathrm{kPa}$ only (Cavanagh, Ulbrecht \& Caputo, 2000). Another worrying fact is that, another famous foot plantar pressure product, the F-scan insole, is reported to produce linear pressure reading only up to $1700 \mathrm{kPa}$ (Luo, Berglund \& An, 1998). In addition to the above mentioned requirements, a report on diabetic ulceration highlighted that patients measured with foot pressure of $\sim 875 \mathrm{kPa}$ or $87.5 \mathrm{Ncm}-2$ may be susceptible to ulceration (Lavery et al., 2003). The development of foot plantar ulcer can be visualized as in the Fig. 4.

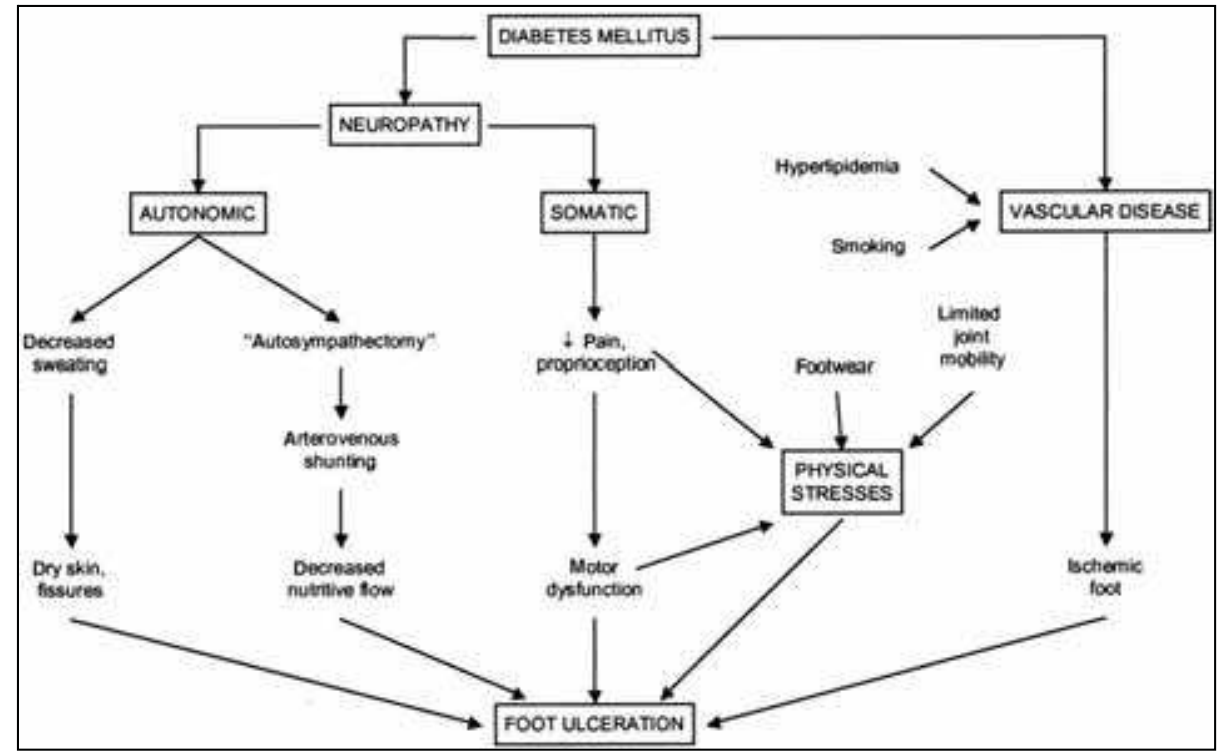

Fig. 4. The factors that lead to foot ulceration among diabetics (Boulton, 2004).

In another report, it is stated that there are three mechanisms that account for the occurrence of ulceration generating pressure (van Schie, 2005). They are: increased duration of exposure to pressures, increased magnitude of pressures and also increased frequency or repetition of exposure to pressure. 
Another very important finding from the literature is the fact that for the measurement of foot plantar pressure among the diabetic sufferers, high resolution measurement is required (Urry, 1999).

\subsection{Section summary}

It is obvious that the need for lower cost in-shoe based pressure sensing devices due to the changing demographics of the world population. Unluckily, the currently available in-shoe sensors are not fully supporting the actual application due to their documented limitations such as limited pressure range, inappropriate sensing area size, hysteresis, linearity, creep and repeatability. Considering all the above requirements and the current limitations, it is obvious that there is a need for an improved design of in-shoe foot plantar pressure measurement device to satisfy the requirements. The great potentials of MEMS technology, which are already proven in other applications, should be explored to achieve this target.

\section{The foot clearance measurement: an overview}

Gait related healthcare cost continues to increase globally partly due to the surge in occurrence of falls among the elderly population. As higher and higher percentage of the world population, including Australia, is made up of the elderly, more and more occurrence of falls is expected each year. In Australia alone, a total of about $\$ 3$ billion is reported to be spent as a result of the falls-related injuries in 1999 (Best \& Begg, 2006). Among the important gait parameters that directly influence the risk of fall among the elderly is foot clearance. It is the spatial parameter of the foot during the swing phase of the gait cycle representing the distance of shoe sole above the ground. In a recent study involving the analysis of the tripping and falls risks among the elderly individuals during walking (Begg et al., 2007; Best \& Begg, 2006; Winter, 1992), it is found that the movement of the foot during mid-swing phase is the most critical event that can initiate the possibility of triprelated fall. This highly important parameter is called minimum foot clearance (MFC). The pattern of foot clearance during gait is depicted in Fig. 5(a) where MFC of below $5 \mathrm{~cm}$ and foot trajectory of up to about $17 \mathrm{~cm}$ is shown (Begg et al., 2007). Unluckily, the current practice in measuring foot clearance mostly requires laboratory settings with the use of reflective or active markers, as shown in Fig. 5(b)-(d), one or more video cameras, threadmill or suitable floor and computer software running on suitable computers (Best \& Begg, 2006). This type of foot clearance measurement may not be representative of real life ADL based measurement in natural settings (Lai et al., 2008), such as at home or outdoor. Problems such as marker slippage may also occur even during laboratory measurement (Best \& Begg, 2006). A more advanced technique is by the use of accelerometers, however, the required calculation that involves double integration of acceleration data yields erratic results due to the effect of drift and errors (Aminian \& Najafi, 2004; Lai et al., 2008). The sensing of MFC using accelerometer based measurement on surfaces that are uneven, bumpy or during stair descend or ascend is obviously problematic as it is not directly measuring clearance but rather calculate it using acceleration data.

As current state-of-the-art instruments are mostly requiring exclusive research, clinical or rehabilitation laboratories settings, plus the fact that they are limited in simulating the real world activities of an individual (Best \& Begg, 2006; Lai et al., 2008), an in-shoe approach is undoubtedly a better option of implementation. 


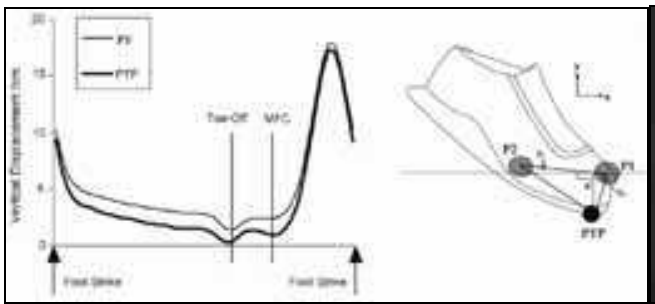

(a)

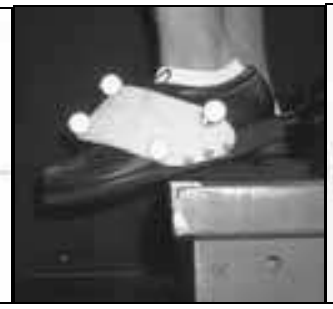

(c)

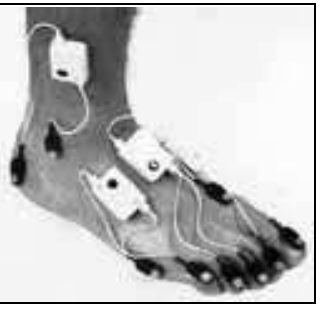

(d)

Fig. 5. (a) Foot trajectory during gait detailing the vertical displacement of foot for one gait cycle showing MFC during mid swing. (b) The markers on the shoe (Begg et al., 2007). (c) A foot clearance measurement during stair decent using passive markers (Hamel et al., 2005). (d) Passive markers (Bontrager, 1998).

\subsection{Shoe integrated foot clearance measurement}

At current, foot clearance measurement is performed in the laboratories or other clinical settings that use markers, video recorders and other bulky equipments. Only markers are placed on the shoes. Other calculation based measurements, but shoe integrated, are actually accelerometer based system (Aminian \& Najafi, 2004; Lai et al., 2008). A shoe integrated direct foot clearance measurement system is the mostly unexplored topic in gait analysis and bio-mechanic research. So far, only one design of shoe integrated direct foot clearance measurement system is reported in the literature (Morris, 2004; Bamberg et.at, 2008). It is as shown in Fig. 6 (a) the sensing walking principle is as detected in fig. 6 (b).

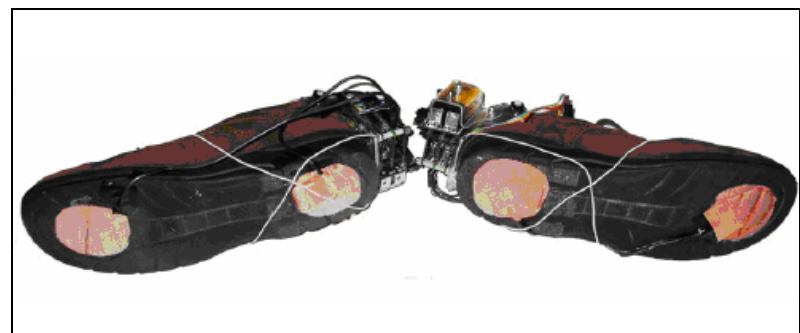

(a)

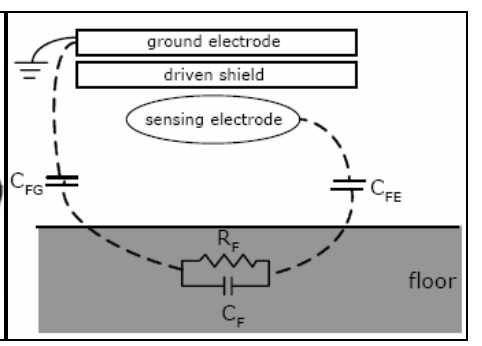

(b)

Fig. 6. (a) Electric field distance sensor electrode attached to the Gaitshoe outsole for foot clearance measurement (Morris, 2004). (b) The working principle of electric field sensing for height determination (Morris, 2004).

Unluckily, the design exhibits several key drawbacks such as follows:

- Low height or clearance measurement range of just up to $5 \mathrm{~cm}$.

- The requirement for minimum 5 layers of electrodes and insulators increases the total thickness of the insole.

- The placement of the conductive electrodes beneath the shoe sole exposes the large area electrode to environmental elements such as water or other materials that may reduce the efficiency and repeatability of the system output.

Due to the obvious limitations, newer systems based on more mobile technology are highly required. As discussed earlier, MEMS offer many great opportunities to close the gap between current requirements and their solutions. Possibility of developing MEMS based 
devices for clearance measurement is therefore considered. For that reason, various distances measurement techniques need to be analysed and their MEMS applicability needs to be identified. This requires that a better understanding of the requirements of this particular measurement is gained. The knowledge is then compared with the actual strengths and weaknesses of MEMS technology to formulate probably the most suitable and efficient implementation.

\subsection{The foot clearance measurement requirement}

In order to enable a thorough and effective study, it is crucial that the measurement and monitoring devices are brought into the real environment where the activities are performed. This means, the ability to be attached to the subject's own shoes is the key requirement. Other general requirements for gait analysis are that the device must not affect movement, untethered and capable of measuring parameters for both feet (Wahab, et al., 2007a, 2007b, 2008; Morris, 2004). This means that the device should be as small and as light as possible. A measurement range of close to $20 \mathrm{~cm}$ is preferable considering maximum toe clearance. However, our current laboratory research suggests minimum foot clearance during the swing phase of walking to be within $3 \mathrm{~cm}$ above the walking surface (Begg et al., 2007).

A portable system attached to the lower limb having a mass of $300 \mathrm{~g}$ or less has been reported to not affect the normal gait (Morris, 2004). For monolithic CMOS integration, only compatible materials and processes must be used. MEMS device normally fabricated of the size range between $1 \mu \mathrm{m}$ and $1 \mathrm{~cm}$ (Liu, 2006). Considering a 120 steps per minute of adult walking, the sampling rate of $75 \mathrm{~Hz}$, or every $13.4 \mathrm{~ms}$ suits well for this application (Morris, 2004). It is reported that the toe clearance above walking surface or ground is minimum around 1.4-1.6 cm during normal walking and around 1.7-2.1 cm during fast walking. On the other hand, the maximum clearance during normal walking is around $5.7-6.9 \mathrm{~cm}$ while during fast walking, it is about 6.3-7.8 cm (Elble et al., 1991).

\subsection{Distance measurement techniques}

Currently, foot clearance measurements are being implemented using electric field sensing technique. However, ultrasound measurement technique is widely used in many other aspect of biomedical and clearance determination application.

\subsubsection{Electric Field Sensing (EFS)}

The electric field sensing technique developed at the MIT Media Laboratory is proven to be successful in various applications such as gait analysis, entertainment, home automation, automotive etc. In general terms of sensing technique, this technique is basically another type of capacitive sensing. Therefore, this technique is a unique technique. More interestingly, there is a microchip produced by Motorola to support the technique (Morris, 2004), indirectly indicating its capability and commercial value. However, the chip is not fabricated with integrated sensor electrodes so as to enable more flexibility to application designers. An implementation of this technique in gait analysis is also reported in the literature (Morris, 2004; Bamberg et al., 2008). The working principle is shown in Fig. 6(b).

This technique involves electric field sensing between two plates of a capacitor, namely the sensing plate or sensing electrode, and the ground plate or ground electrode. The sensing electrode is connected to the signal transmitting circuitry to generate an electrical field from a sinusoidal AC signal. On the other hand, the ground electrode is connected to 
the ground of the circuitry. The floor, as the target of which its distance from the sensing plate is to be measured, contributes to the change in capacitance reading. The change is sensed by the sensing electrode. As the distance between the floor and sensing electrode is varied, the measured capacitance is also varied. Even though this technique is quite simple, it is highly capable of producing quality data for distance measurement. Despite its simplicity and high accuracy, its use is limited by the sensing electrode size requirement. This fact agrees well with the published design guideline (Sieh \& Steffen, 2006).

\subsubsection{Ultrasonic Sensing (US)}

Initially, ultrasound is used for tracking the seabed following the Titanic disaster in 1912 from which it then developed into what is called today as Sound Navigation and Ranging (SONAR) (Smith \& Schoenwald, 1984). The application of ultrasound for distance measurement is basically the same with the underwater SONAR, the only difference is the speed of measurement. The speed of ultrasound in air is around $345 \mathrm{~ms}^{-1}$. A number of system level and transducer level design for ultrasonic range measurement realization are reported in the literature such as in automotive and robotic applications (Carullo \& Parvis, 2001; Song, Chen \& Huang, 2004; Kajita \& Tani, 1997). Examples of ultrasonic technique used are such as robotic obstacle avoidance (Bank, 2002), robot height above ground (Kajita \& Tani, 1997), car reverse parking assistance (Turner \& Austin, 2000), car height above road surface determination (Carullo \& Parvis, 2001). It is also used in other assistive technology for the disabled such as assistance for the blind (Ando, 2003) and wheelchair (Simpson et al., 2004; Dutta \& Fernie, 2005). Ultrasonic sensing is among the mostly used techniques in biomedical fields, inclusive of several laboratory measurements of gait (Wahab et al., 2008; Begg et al., 2007; Sabatini \& Colla, 1998; Weir \& Childress, 1997; Abulaffio, Gelernter \& Pillar, 1996). Other biomedical applications include therapy, 3D imaging and arterial diameter determination and other biomedical uses (Ling et al., 2007; Coleman et al., 2004). The interest in ultrasound technique is increasing due to its non-ionising or nonelectromagnetic characteristic (Smith \& Schoenwald, 1984). It is thus a safer method as compared to the ionising ones. Interestingly, it is said that the widespread use of ultrasound for distance measurement is sparked by the famous pocket-sized Polaroid camera developed in the late 1970s. This very portable technology relies on a $5 \mathrm{~V}$ battery to produce up to $400 \mathrm{~V}$ of pulse-train signal for the excitation of the camera's capacitive ultrasound transducer during auto-focus operation (MacIsaac \& Hamaalainen, 2002). With this technology, the camera is able to sense an object $11 \mathrm{~m}$ away. Polaroid produces similar ultrasound ranging system for the market and thus enabled development of other ultrasound distance measurement systems for various applications by other companies. It is becoming the precursor for development of ultrasonic ranging systems (Smith \& Schoenwald, 1984) and is then considered as one of the enabling technology of the 90's (Grace, 1991).

It is also said that ultrasound signals are used as most of surfaces and objects are good reflectors of ultrasound (Turner \& Austin, 2000). Two applications that successfully measure height above ground surface in real outdoor environments are as shown in the Fig. 7. The figure proves that it is highly probable that ultrasound based system is capable of measuring foot clearance above ground. 


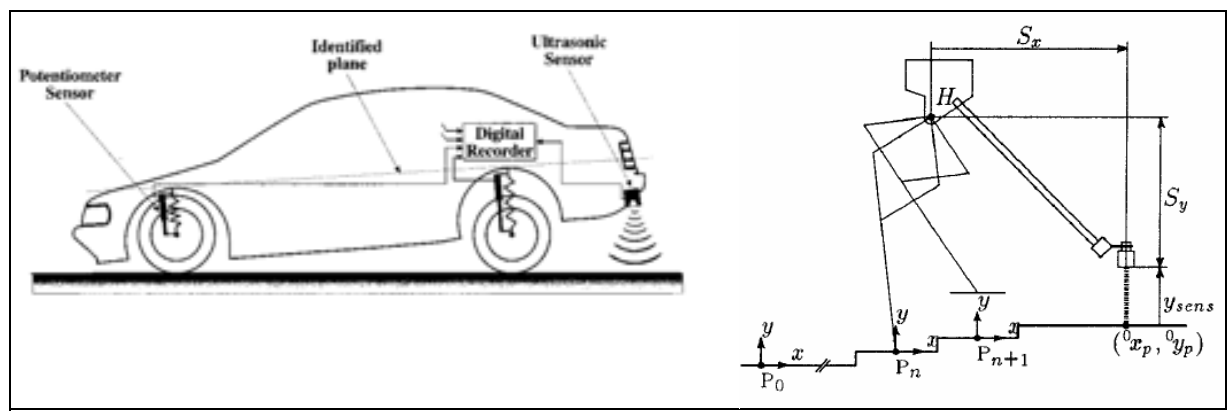

Fig. 7. (Right) Ultrasound sensor is used by robot to measure height (ysens) with resolution of $0.3 \mathrm{~mm}$ (Kajita \& Tani, 1997), (Left) A $40 \mathrm{kHz}$ Ultrasonic car height measurement for $0^{\circ} \mathrm{C}$ $40^{\circ} \mathrm{C}$ operating temperature, $0.1 \mathrm{~m}-0.6 \mathrm{~m}$ range and better than $1 \mathrm{~mm}$ resolution (Carullo \& Parvis, 2001).

Considering that ultrasound ranging systems are already bearing fruit in mobile ranging application, height above ground application and other gait analysis applications with good distance range, it is therefore a very promising technology for the target application. Several techniques of distance measurement for ultrasound ranging system were proposed in the literature. These include time-of-flight (tof), continuous wave phase-shift method, and also combination of tof and phase (Gueuning et al., 1997). For example, in using tof method as shown in Fig. 8, after an ultrasound signal is transmitted by a transmitting transducer (transmitter), the distance, 1 , can be calculated based on the time, $t$, taken by the ultrasound echo to return to the receiver.

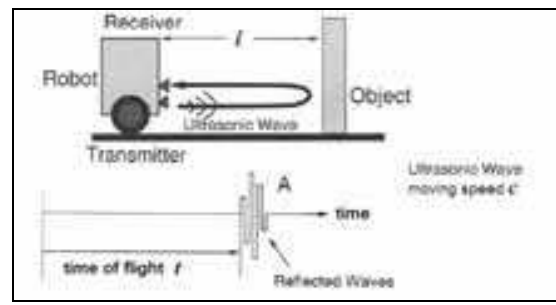

Fig. 8. A simple time of flight concept (Ohya, Ohno \& Yuta, 1996).

It is generally understood that increasing ultrasound frequency improves detection resolution (Coleman et al., 2004; Yano, Tone \& Fukumoto, 1987) and reduces dead zone length (Bruinsma et al., 2006). However, the high attenuation in air which increases with frequency is a great challenge (Magori, 1994; Yano, Tone \& Fukumoto, 1987). It is reported that $1 \mathrm{MHz}$ signal can theoretically measure distance up to $20 \mathrm{~cm}$ (Yano, Tone \& Fukumoto, 1987), while $2 \mathrm{MHz}$ signal can measure up to few centimeters (Noble et al., 1995). Recently, very high frequency ultrasonic transducers are reported for various high resolution biomedical applications. A more detail discussion on this technology is provided in the next section of the chapter.

\subsection{Section summary}

From the extensive reference in the literature, it is finally obvious that a direct measurement of foot clearance is highly needed. Unluckily, the instrumentation technology is not paying 
enough attention to this need for unknown reason. The need for it is increasing due to the changing global population demography. Therefore, this research is trying to close the obviously expanding gap. Two suitable distance measurement techniques are identified for consideration. Each of the technique has its own strength and weaknesses. Therefore, further analysis on the mentioned techniques is warranted. Next, consideration is going to take into account the limitation and strength of MEMS. In this regard, the applicability of the three techniques will again be evaluated after adaptation to suit MEMS technology requirement is made on them.

\section{MEMS technology for gait measurement}

In evaluating suitability of an identified distance and pressure measurement methods for MEMS realization, a closer look into each of the technologies are necessary. This includes the structural requirement, the operational requirement and the material requirement.

\subsection{MEMS clearance sensor}

Results from numerical simulations to evaluate the two distance measurement techniques, which include, electric field sensing and also ultrasonic sensing are already presented and discussed. Summary of the results showing some important aspects of the two measurement techniques are presented in Table 1 for comparison.

\begin{tabular}{|l|c|l|}
\hline \multicolumn{1}{|c|}{ Key observation } & EFS & \multicolumn{1}{c|}{ US } \\
\hline $\begin{array}{l}\text { Sensing range with up to 1 } \\
\mathrm{cm}^{2} \text { sensor area }\end{array}$ & $\begin{array}{c}15-20 \mathrm{~cm} \\
\text { @ } 1 \mathrm{~cm}^{2}\end{array}$ & $\begin{array}{l}\text { Huang,2000) } \\
\sim 25 \mathrm{~cm} @ 1 \mathrm{~cm}^{2} \text { using CMUT (Almqvist } \\
\text { et al.,2002) } \\
1 \mathrm{~m} \mathrm{@} 1 \mathrm{MHz}, 0.49 \mathrm{~cm}^{2} \text { and 24 cm @ 2 } \\
\text { MHz, 0.49 } \mathrm{cm}^{2} \text { (Ergun et al.,2006) }\end{array}$ \\
\hline $\begin{array}{l}\text { Previously reported as } \\
\text { MEMS or micromachined }\end{array}$ & No & $\begin{array}{l}\text { Yes (Kuratli \& Huang, 2000; Yaralioglu, } \\
2003)\end{array}$ \\
\hline $\begin{array}{l}\text { Ever used in foot clearance } \\
\text { measurement }\end{array}$ & $\begin{array}{l}\text { Yes } \\
\text { (Morris, 2004) }\end{array}$ & No \\
\hline $\begin{array}{l}\text { Signal to distance } \\
\text { relationship (linearity) }\end{array}$ & Non-linear & Linear \\
\hline $\begin{array}{l}\text { Remarks based on the } \\
\text { analysis results in Section 3 }\end{array}$ & $\begin{array}{c}\text { Not suitable } \\
\text { due to size }\end{array}$ & $\begin{array}{l}\text { Ultrasound of around 1 MHz may offer } \\
\text { good resolution and signal strength }\end{array}$ \\
\hline $\begin{array}{l}\text { Suitability for MEMS, } \\
\text { taking range dependent } \\
\text { sensor size as limit }\end{array}$ & Not suitable & Suitable \\
\hline
\end{tabular}

Table 1. Comparison of the two techniques.

As presented in Table 1, the comparison between the two techniques shows that high resolution ultrasound ranging is the best choice due to the fact that it is capable of sensing the distance of up to $30 \mathrm{~cm}$, which is the highest range achieved if MEMS size is the key criteria. If the most recently published experimental work by Ergun et al. (2006) is considered, there is no doubt that ultrasound is the best choice for implementation. Obviously, the ultrasonic measurement technique is not only suitable for MEMS, it is also 
theoretically proven to be able to measure the foot clearance during most of gait related activities too. In MEMS technology, ultrasound sensors are called Capacitive Micromachind Ultrasonic Transducer (CMUT) if it operates on capacitive technique. This result indicates that ultrasound is a very promising technique. Considering those facts, ultrasound is thus selected in this work for the design of a foot clearance measurement sensor.

The target of this work is to design a sensor for use in a portable gait analysis and fall prevention system. To ensure practicality of the design, an application based design specification is developed considering the application requirements. The specifications are:

Operating frequency

The target operating frequency of between $500 \mathrm{kHz}$ and $1 \mathrm{MHz}$ is a good choice. As discussed in the previous section, to eliminate the ultrasound noise, frequencies above 500 $\mathrm{kHz}$ is compulsory. On the other hand, frequencies more than $1 \mathrm{MHz}$ may cause significant signal degradation of more than $100 \mathrm{~dB}$. Even though good dynamic range can be realized theoretically, it is better to allow more signals to noise margin (SNR) figure, possibly more up to $30 \mathrm{~dB}$. In the selected frequency range, however, $1 \mathrm{MHz}$ signal may offer higher resolution due to its low wavelength. Nevertheless, if system level algorithm optimization is considered, even low frequency ultrasound can be used to produce sub-millimeter resolutions, as discussed in the preceding section.

Supporting the required sampling frequency

The sensor should be capable of supporting the required $75 \mathrm{~Hz}$ distance sampling frequency. Which means, a distance value must be obtained every $13.3 \mathrm{~ms}$. This is not a problem with ultrasonic technique as, consider the worst case scenario where $30 \mathrm{~cm}$ foot clearance is measured (ultrasound speed of $340 \mathrm{~ms}^{-1}$ ) by calculation, the TOF is merely 1.765 ms. In this case, about seven distance measurement can be performed every $13.3 \mathrm{~ms}$, which proves the compliance with the requirement.

\section{Foot clearance range}

The sensor must be designed to be able to measure foot clearance above ground/floor of at least $5 \mathrm{~cm}$.

A structural cross-sectional view for CMUT is given in Fig. 9(a) while its electromechanical model is depicted in Fig. 9(b). To understand the CMUT electromechanical behaviour, it is imperative to firstly analyze the fundamental equation for capacitance and then use it together with the electromechanical model.

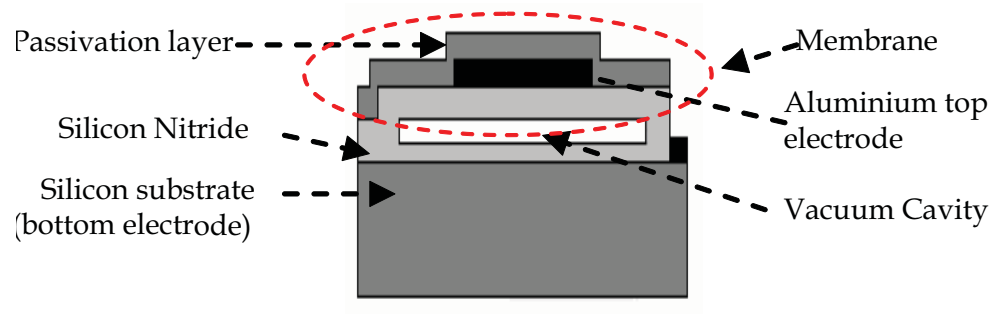

(a)

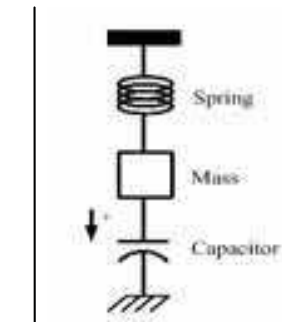

(b)

Fig. 9. (a) A cross-sectional view of a CMUT (adapted from Ergun, Yaralioglu \& KhuriYakub, 2003). (b) The lumped electromechanical model for CMUT. 
The reflected signal activates vibration of the receiver transducer and alters the capacitance value of the transducer structure. The readout circuit detects the capacitance change for appropriate processing of distance information. Considering an ultrasonic measurement technique, a system view of the proposed model is shown in Fig. 10.

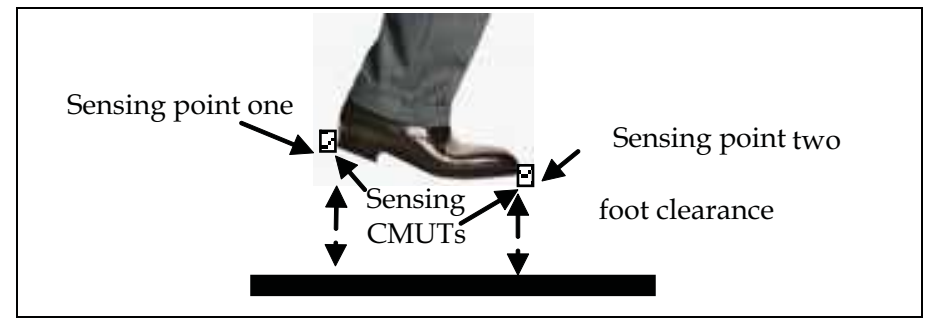

Fig. 10. A possible implementation using two points sensing.

There are two critical measures of a MEMS CMUT. The two are collapse voltage, $\mathrm{V}_{\text {col }}$ and resonance frequency, $\mathrm{f}_{\mathrm{r}}$. The collapse voltage indicates the possible values of operating voltage while resonance frequency determines the signal characteristic. By referring equation (1), collapse voltage, $V_{\text {col }}$ can be determined. In this equation, $Y_{0}$ is the young modulus of the membrane material, $t_{g}$ is a gap/cavity height, $t_{m}$ is the membrane thickness, $\varepsilon_{0}$ is the permittivity of free space, $8.854 \times 10^{-12} \mathrm{~F} / \mathrm{m}$ and $r$ is the membrane radius.

$$
V_{c o l}=\sqrt{\frac{128 Y_{0} t_{m}^{3} t_{g}^{3}}{27 \varepsilon_{0}\left(1-\sigma^{2}\right) r^{4}}}
$$

The deflection of membrane at collapse voltage can be referring to the Fig 11 .

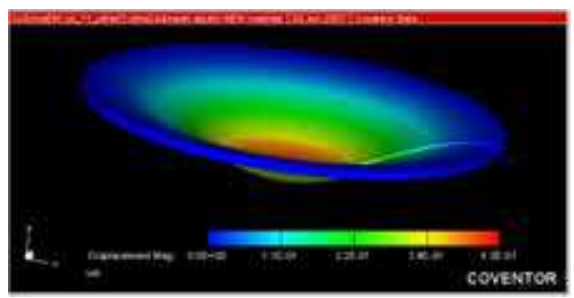

Fig. 11. The deflection of membrane at collapse voltage.

While, for resonance frequency, $\mathrm{f}_{\mathrm{r}}$ is shown in equation (2) where $\rho_{m}$ is the material's density, $d_{m}$ is its thickness, $d_{g}$ is a sacrificial layer of thickness, $\rho_{0}$ is air density, and $v_{s}$ is sound speed in air. Table 2 shows some good calculation results using (2) and yet it is very simple and fast.

$$
f_{r}=\frac{1}{2 \pi} \sqrt{\frac{\rho_{o} v_{s}{ }^{2}}{\rho_{m} d_{m} d_{g}}}
$$

All CMUT on silicon design work is performed using the industry standard Coventorware tool (Coventor Inc., 2006). As nitride layer is used as the membrane structure material, therefore the top and bottom electrode will never be touched during membrane deflection as it vibrates following the AC voltage excitation. 


\begin{tabular}{|c|c|c|l|}
\hline $\begin{array}{c}\text { Membrane } \\
\text { Material }\end{array}$ & $\begin{array}{c}\text { Structure } \\
\text { dimension }\end{array}$ & $\begin{array}{c}\text { Calculated } \\
\text { frequency }\end{array}$ & \multicolumn{1}{c|}{ Comments } \\
\hline Silicon Nitride, & $\begin{array}{c}d_{g}=0.5 \mu \mathrm{m} \\
d_{m}=0.5 \mu \mathrm{m}\end{array}$ & $2.19 \mathrm{MHz}$ & $\begin{array}{l}\text { Comply with calculation in example of } \\
\text { (Eccard, Niederer \& Fischer, 1997) }\end{array}$ \\
\hline Silicon Nitride, & $\begin{array}{c}d_{g}=1.0 \mu \mathrm{m} \\
d_{m}=1.0 \mu \mathrm{m}\end{array}$ & $1.11 \mathrm{MHz}$ & $\begin{array}{l}\text { In close agreement with result in } \\
\text { (Jones et al., 2001) }\end{array}$ \\
\hline Silicon Nitride, & $\begin{array}{c}d_{g}=0.3 \mu \mathrm{m} \\
d_{m}=0.2 \mu \mathrm{m}\end{array}$ & $1.6 \mathrm{MHz}$ & $\begin{array}{l}\text { About 10\% difference with measured } \\
\text { in (Ladabaum et al., 1998) }\end{array}$ \\
\hline $\mathrm{Al}_{2} \mathrm{O}_{3}$ & $\begin{array}{c}d_{g}=0.75 \mu \mathrm{m} \\
d_{m}=0.6 \mu \mathrm{m}\end{array}$ & $4.1 \mathrm{MHz}$ & $\begin{array}{l}\text { About 5\% difference with measured in } \\
\text { (Liu et al., 2004) }\end{array}$ \\
\hline Silicon Nitride, & $\begin{array}{c}d_{g}=1.0 \mu m \\
d_{m}=1.1 \mu \mathrm{m}\end{array}$ & $1.05 \mathrm{MHz}$ & $\begin{array}{l}\text { Calculation for the optimized } \\
\text { frequency }\end{array}$ \\
\hline
\end{tabular}

Table 2. Design examples using (2) and comparison with measurements in relevant literature.

Process for developing the transducer is custom sequenced using the available process libraries in Coventorware Process Editor module. The sequence starts with a silicon substrate and followed by a nitride deposition of $0.5 \mu \mathrm{m}$. A conducting polysilicon of $0.5 \mu \mathrm{m}$ is then deposited, patterned to form the bottom plate of $45 \mu \mathrm{m}$ diameter. Following this, the unwanted polysilicon areas are removed by etching.

The release of the membrane structure is performed next where all sacrificial material beneath the structural nitride is removed. This is done through an opening at the side of the wall where the sacrificial layer is exposed. A nitride seal is then deposited in low pressure process to seal the hole left by sacrificial removal leaving cavity in near vacuum.

\subsection{MEMS foot presure sensor}

Firstly, the shape is determined based on the piezo-resistance sensing requirement. Based on literature, square shape membrane is capable of providing high stress areas, as high as 1.64 times as compared to a circular one (Berns et al., 2006). Mathematical modeling is the first major step of the design with an aim of determining the membrane thickness and side length that can perform pressure measuring task for the specified range. The values of its thickness, length and width must allow linear membrane deflection within the pressure range while ensuring no mechanical damage or fracture.

Silicon as a mechanical material has long being studied and the material characteristics documentations for it have long been published. Silicon is a very promising material in micro-scale sized. These proven facts further boost the exploration activities around silicon based MEMS device realization. Key properties that are important in selection of MEMS materials are such as Yield Strength, Mechanical Hysteresis and Fatigue Failure. Yield Strength is the point when the material starts to exhibit plasticity, which mean, it will elongate un-proportionally the same way a plastic material reacts under external force. This is true in many materials such as steel. In contrast, silicon is a perfect elastic material so that it exhibits a linear or proportional stress-strain relationship. In fact, it yields catastrophically when stress of more than its Yield (or Fracture) Strength figure is applied (Jia \& Madou, 2006). Silicon exhibits almost double the Yield Strength as compared to Steel. In addition, perfect elasticity also indicates another great advantage of silicon in sensing performance as it means no Mechanical Hysteresis. As silicon is not exhibiting deformation, it is very insensitive to fatigue and creep (Jia \& Madou, 2006). Therefore, in terms of Mechanical 
Hysteresis and Fatigue Failure, silicon is showing significant advantages as none of both characteristic being exhibited (Bryzek et al., 2006).

Fig. 12 shows how MEMS pressure sensor is used in Exoskeleton and Parotec insole application.

Fig. 13 shows a crossection of a MEMS pressure sensor.

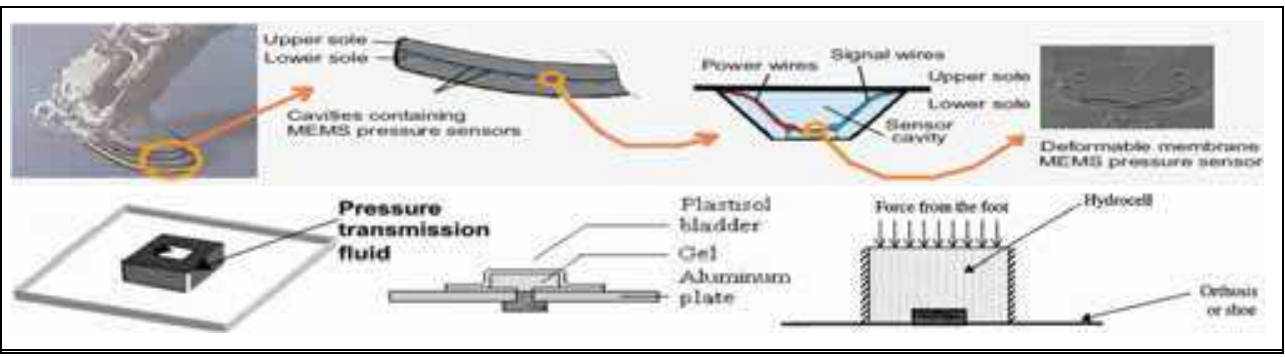

Fig. 12. A Piezoresistive MEMS pressure sensor in action: (Top) the insole of a Robot at University California, Berkeley (Wheeler et al., 2006), (Bottom-Right) The Parotec hydrocell insole (Chesnin, Selby-Silverstein \& Besser, 2000), and (Bottom-Left \& Middle) a biomechanical pressure sensor (Lee et al., 2001).

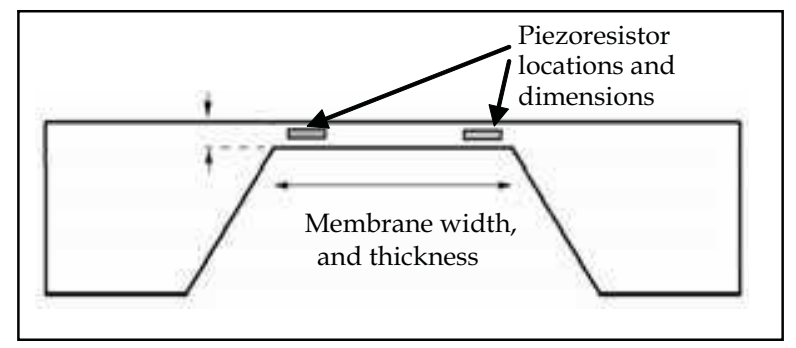

Fig. 13. A conceptual design of a MEMS pressure sensor in a crossectional view.

So, it is highly crucial that the effect of membrane thickness and membrane size on the pressure induced membrane deflection and membrane stress is thoroughly studied at the initial stage. As the output of the sensor is highly dependent on the deflection characteristic parameter and resistance change parameter, the output voltage linearity is thus affected by both parameters too. According to the foundry design guidelines (MultiMEMS, 2007), the piezoresistance change and stress relationship is governed by the linear equation given in (3). On the other hand, equations (4) and (5) relate piezoresistor stresses to the applied pressure in small deflection regime (Gong \& Lee, 2001). In these equations, $R$ and $R_{o}$ are the piezoresistor's resistance value when external pressure is applied and the piezoresistor's resistance without any applied pressure respectively, $\Pi_{L}$ and $\Pi_{T}$ are the piezoresistance coefficient for longitudinal and transversal directions respectively, $h$ is membrane thickness, $L$ is membrane edge length, $e_{m}$ is the $m$-th coefficient as given by Gong \& Lee (2001), $v$ is Poisson ratio, $l_{p}$ is piezoresistor's length, $\sigma_{T}$ is the average transversal stress across the piezoresistor and $\sigma_{L}$ is the average longitudinal stress along the piezoresistor. The stress components are shown in Fig. 14. Value of $e_{m}$ coefficients for particulars $e_{1}$ is -0.37 , while for value of $e_{m}$ coefficients for particulars $e_{3}$ is 0.0379 and for value of $e_{m}$ coefficients for particulars $e_{5}$ is 0.0175 . 


$$
\begin{gathered}
R=R_{0}\left(1+\Pi_{L} \sigma_{L}+\Pi_{T} \sigma_{T}\right) \\
\sigma_{T}=\frac{-48}{\pi^{4}} P\left(\frac{L}{h}\right)^{2}\left(\frac{L}{l_{p}}\right) \sum_{m=1,3,5}^{\infty} \frac{e_{m}}{m}(-1)^{\frac{m-1}{2}} \sin \left(\frac{m \pi l_{p}}{2 L}\right) \\
\sigma_{L}=v \sigma_{T}
\end{gathered}
$$

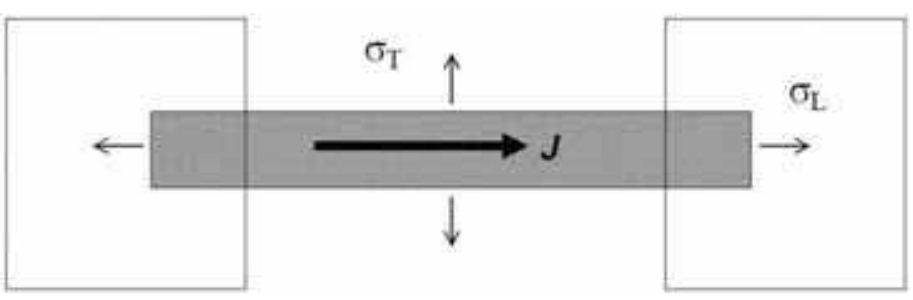

Fig. 14. Transversal and longitudinal stresses acting on a piezoresistor with respect to the current flow direction J (Zamali \& Talghader, 2006).

The importance of membrane deflection lies on the fact that since the resistance change due to deflection is already linear in nature, the deflection characteristic therefore becomes the sole determining factor for the linearity of the sensor output. It is reported that the magnitude of membrane deflection is linear with the applied pressure when the deflection is still in the small deflection regime. The membrane is said to operate in this regime as long as the deflection is less than 25 to $50 \%$ of its thickness (Wang et al., 2005, Gong \& Lee 2001). For comparison, two equations representing the applied pressure and square membrane deflection are given in equation (6) and (7) (Linlin, Chen \& Guangdi, 2006). The former equation is for small deflection regime while the latter represents the large deflection regime. Maier-Schneider, Maibach \& Obermeier (1995) also reported large deflection relationship in even more detail, complete with its derivation. As can be seen, the small deflection equation represents a linear relationship, as opposed to the non-linear cubic equation for large deflection. In these equations, in addition to the previously defined symbols, $v$ is Poisson ratio, $a$ is half of edge length, $\sigma_{0}$ is the intrinsic stress of the membrane, $E$ is the Young's Modulus and $w_{0}$ are the maximum deflection of the membrane.

$$
\begin{gathered}
P=\left(3.41 \frac{h \sigma_{o}}{a^{2}}+4.31 \frac{E h^{3}}{a^{4}\left(1-v^{2}\right)}\right) w_{0} \\
P=3.04 \frac{h \sigma_{0}}{a^{2}} w_{0}+1.88 \frac{E h}{a^{4}} w_{0}^{3}
\end{gathered}
$$

In addition to the linearity requirement, the mathematical analysis is also important in determining another key design specification, namely maximum pressure measurable. This is due to the fact that the magnitude of total membrane stress determines the maximum pressure value that the membrane may be able to withstand, beyond which the membrane breaks. For that reason, the point of rupture which is also known as Fracture Stress must be taken into account in the determination of suitable membrane dimension. Therefore, the relationship between membrane dimensions and its deflection and stress is extensively analyzed. 
After extensive mathematical analysis, the final designs are then determined which consists of only thick membranes. This is due to their compliance with the physical design requirements as identified in the stated foundry maximum size limits, the derived foundry rule based minimum size limit, deflection linearity modelling result and stress withstanding capability modelling result. Finally, only few membrane sizes are chosen to be modeled in silicon.

These selected designs include the ones using $100 \mu \mathrm{m}, 200 \mu \mathrm{m}$ and $278 \mu \mathrm{m}$ membranes. Out of the three sensors, the $100 \mu \mathrm{m}$ sized sensor is the one that can measure wider pressure range, but with less sensitivity and signal magnitude. Whereas, the $200 \mu \mathrm{m}$ and $278 \mu \mathrm{m}$ ones are also designed and simulated for comparison and further studies purposes Silicon modeling involving the use of MultiMEMS processes is implemented in Coventorware ${ }^{\mathrm{TM}}$ and the three dimensional models are generated for performance analysis.

In using the process steps to model the devices, it is necessary to perform the three model design stages. These stages includes identification of key structural layers required for successful and effective implementation of finite element analysis, layout specifications of the required layers and finally meshing design requirement. Fig. 15 show 3D model and its mesh. In actual design, all four corners of the model are symmetrical.

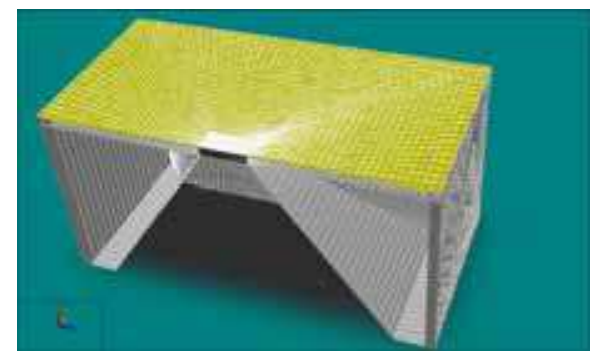

Fig. 15. 3D model and its mesh. In actual design, all four corners of the model are symmetrical.

Supporting the mathematical modeling results are the more computational intensive computer based Coventorware ${ }^{\mathrm{TM}}$ results. The Von Mises stress values are considered a good indicator to determine whether a design is suitable or not (Bistue et al., 1997). As the Von Mises stress is the effective stress acting in the membrane, if the membrane Von Mises stress is more than the fracture stress, the material will break (Cardenas et al., 2007). The Von Misses stress is observed at its maximum at the center of the membrane where deflection is at its peak. However, the value for the $100 \mu \mathrm{m}$ is merely $13 \mathrm{MPa}$.

The middle of the four sides of the membrane also show significant stress values of about 6 $\mathrm{MPa}$. This much lower stress value shows that the design is very suitable for the targeted range and it is highly probable that in practical, even if a pressure of more than $3 \mathrm{MPa}$ is applied, the membrane is still far from the risk of rupture. In another observation, the resonance frequencies of the membranes as obtained from modal analysis are in the megaHertz zones, putting the device in a very safe operation zone, as far as harmonics related error of gait measurement is concerned. These high resonance frequencies are expected considering the membranes thickness. The Von Mises Stress maximum values are given in Table 3. As can be seen, the magnitude of stress is very far from the fracture values for all of the sensors and this observation supports the mathematical analysis. The applied pressure is from 0 to $3 \mathrm{MPa}$ and the observed stresses for the 100, 200 and $278 \mu \mathrm{m}$ membranes are colour coded for easy observation. The results from FEA simulation, encompassing various 
membrane stresses is kept in the Coventorware design database. This database can be accessed from other Coventorware modules for further analysis too. In the next section, the database is retrieved to perform a sensor system level analysis.

\begin{tabular}{|l|c|c|c|}
\hline Sensors & $100 \mu \mathrm{m}$ & $200 \mu \mathrm{m}$ & $278 \mu \mathrm{m}$ \\
\hline Von Mises Stress & $13 \mathrm{MPa}$ & $58 \mathrm{MPa}$ & $96 \mathrm{MPa}$ \\
\hline
\end{tabular}

Table 3. The Maximum Von Mises Stress

Using the optimized locations and dimension, the relationship of the output voltage and the applied pressure is obtained. The optimized relationship of the output voltage and pressure when the applied pressure is varied from $0 \mathrm{~Pa}$ to $3 \mathrm{MPa}$ on the membrane is superbly linear. The results as presented in the optimization section are hereby verified. The sensor output is again increased 100 times by use of operational amplifier circuit. Another important observation but not directly shown is that, as predicted in the calculation, the deflection is linearly proportional to the pressure magnitude.

The foundry fabrication completes in about six months. Dice in Level 0 Package are shown in a close-up view of the delivered items as shown in Fig. 16(a). Dimensions of the dice are roughly $3 \mathrm{~mm} \times 3 \mathrm{~mm} \times 1.5 \mathrm{~mm}$. It is obvious that the scales on the ruler behind the dice indicate $3 \mathrm{~mm}$ die side length. As the holes are drawn for each of the sensors, three holes can be seen on one side of the Level 0 Package (the die on the left of the photograph). On the opposite side of the dice, a cavity is seen above the aluminium interconnection lines. Process variations that may cause thicker than $23.1 \mu \mathrm{m}$ membranes and also reduced piezoresistance of the piezoresistors are also reported by the foundry (MultiMEMS, 2009b).

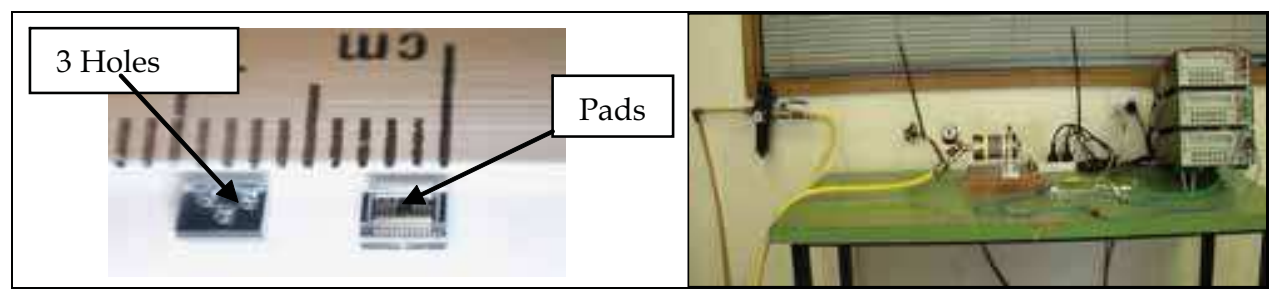

Fig. 16. The produced dice (in Level 0 Package) from the foundry.

The development of custom mechanical set-up which is basically consists of a pressure chamber, its stand, a valve, several steel pipe components (threaded end caps, Y connectors etc) and a pressure gauge is also completed prior to the mechanical laboratory testing. Initially, the design uses RF signal transmission but as metal blocks RF signal and to avoid environmental related attenuation, wired solution is later chosen. Wired connection also provides more direct, accurate and highly reliable readings.

A high pressure industrial grade compressed air system is used to supply pressurized air into the chamber through the valve and the $\mathrm{Y}$ connector. To ensure gradual increase of pressure in the chamber, the valve is manually controlled. Air pressure is gauged using the readily fitted pressure gauge as its pressure sensing mechanism is also exposed to the pressurized air in the chamber through the other branch of the $Y$ connector. A photograph showing the complete mechanical testing set-up is given in Fig. 16(b).

Pressure is increased gradually from slightly above the atmospheric pressure up to the maximum pressure allowed by the calibration certificate. Fig. 17 shows the graphs of the output of the three pressure sensors. The measurements begin with 20 psi level, which is 
equivalent to $137.9 \mathrm{kPa}$ and ends at $135 \mathrm{psi}(930.825 \mathrm{kPa})$ due to calibration limitation. It is clear that the pressure and output voltage relationship of all the sensors are very linear as expected from simulation result. The system is powered by a $9 \mathrm{~V}$ battery. Most interestingly, the results prove the quality of the designed piezoresistive pressure sensors in producing very linear pressure to voltage relationship, which is the key objective of this research.

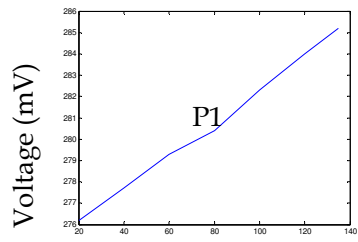

Pressure (psi)

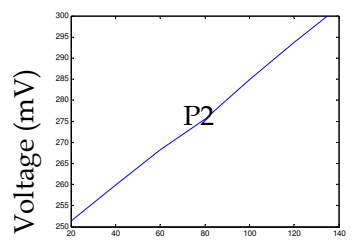

Pressure (psi)

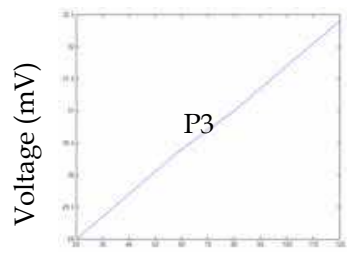

Pressure (psi)

Fig. 17. The graphs produced from the recorded experimental pressure and output voltage relationship. The voltages are not amplified.

\section{Chapter summary and discussion}

The current state of gait analysis instrumentation is discussed. It is proven that newer generation of gait analysis/biomechanical instrumentation is produced to ensure real time and efficient measurement. Therefore MEMS technology is explored. In this chapter, two MEMS based sensors, one for foot plantar pressure measurement, and the other one for foot clearance measurement are discussed.

In concluding this chapter let us begin with foot clearance measurement. Two most suitable distance measurement techniques are studied and presented for consideration towards realization of a MEMS based foot clearance sensing device. They are firstly optimized for MEMS according to the MEMS technology requirement, in aspects such as structural materials and size. They are then evaluated in terms of suitability for foot clearance measurement application by means of maximum distance and linearity simulations. The requirements for gait analysis application are also presented and used as the guidelines for the selection. The analysis of the simulation results and comparisons with the measured data in literature are also included. Ultrasound-based distance measurement technique is preferred due to its proven practical use in similar other applications and also due to good simulation results in terms of maximum foot clearance that can be measured. In addition, it is also generally showing linear relationship between clearance and tof signal.

Various ultrasound generation and sensing mechanisms such as piezoelectric and capacitive are studied. The selection of sensing mechanism is based on aspects of fulfilment of gait analysis needs, competitiveness of manufacturing cost and capability for total integration with circuitry for performance and system miniaturization. Among the gait analysis needs include small size, light weight and suitable range. In addition to dependency of sensing range on signal frequency, the measureable range is also dependent on signal strength, so, the right choice of elelctromechanical coupling factor is important when biasing the CMUT. This characteristic offers an additional flexibility in terms of range and power management. 
As a result, a CMOS compatible CMUT realization is chosen and explored. This includes the design requirement and specification, mathematical analysis, computer simulation and finally design implementation of a CMOS compatible CMUT tailored for ultrasonic foot clearance measurement. All results pertaining to various steps are presented and discussed. Some key parameters of the CMUT are also included.

In addition to the many device related advantages inherited from the use of CMUT technology, the system level strengths, such as signal processing, will be further enhanced due to its CMOS compatibility. The literature proves that CMUT dedicated CMOS circuits such as for signal processing is already studied and developed (Wygant et al., 2004). The inclusion of sensors, signal processing and compensation circuitry, memory and wireless communication capability in one chip as an SoC may produce a high performance ultrasonic system (Svilainis \& Dumbrava, 2005; Schweinzer \& Elmer, 2005).

In short, the objective of the study which is to explore MEMS applicability for the measurement of foot-to-ground clearance has been achieved and demonstrated. A suitable technique is identified, and as a result, an ultrasonic transducer suitable for foot clearance measurement system is fully designed, modelled, and implemented. The transducer/sensor is optimized for gait analysis application. As it is CMOS compatible, further works on CMOS circuitry will enable system level integration for the realization of an integrated high performance system for foot clearance measurement.

Next, let us recall a discussion on foot plantar pressure. The testing and characterization of a silicon MEMS pressure sensor for biomedical application is also described. Every steps of the project is explained, including the internal pads interconnection, Level 0 Package design, GDS II foundry file generation for tape-out, wirebonding from Level 0 Package pads to Level 1 Package pins, Level 1 Packaging, printed circuit board design, amplifier circuit design, complete circuit integration on printed circuit board, electrical testing system design and testing implementation and finally mechanical testing system design and testing implementation. All the steps are successfully performed. The results of each of the steps are recorded, displayed and discussed in detail. The key findings of the work in this chapter cover the electrical and mechanical testing results.

From the electrical design and testing aspects of the fabricated pressure sensor, the resistance of the piezoresistors are of great importance and are thus is discussed in detail. To verify this, the measured results are compared with the calculated values from the design stage. The comparison shows very acceptable resistance variations across three different sensor designs. The source of variation is identified as resulting from foundry process deviation, according to the fabrication report from the foundry (MultiMEMS, 2009b). The result proves that the layout design stage is very important to ensure achievability of the target specification as outlined during the design and optimization stage.

Further work then includes the study of the sensors' response under varying pressure. This is the final part of the research where the sensing capability is studied and discussed. Due to the nature of the measurand, this final job is also very demanding, especially in the aspects of mechanical preparation. A specialized pressure chamber is designed solely for this purpose with the sensor board size and cabling requirements in mind. Finally, the much awaited sensor characterization results are performed and the recorded results prove that the sensors' responses are very linear.

With the completion of the pressure sensor characterization, the research work is now completed successfully. Results from both finite element analysis and experimental works 
have proven that the sensors are linear and capable of producing high signal values. Therefore, the mission is now accomplished.

\section{References}

Abu-Faraj, Z.O., Harris, G.F., Abler, J.H. and Wertsch, J.J. A Holter-type, 1997. 'Microprocessor-based, rehabilitation instrument for acquisition and storage of plantar pressure data', Journal of Rehabilitation Research and Development, vol. 34, pp. 187-194.

Abulaffio, D.R., Gelernter, I \& Pillar, T., 1996. 'An ultrasonic-operated kinematic measurement system for assessment of stance balance in the clinic', Clinical Biomechanics, Vol. 11, pp. 173-175.

Aminian, K. and Najafi, B., 2004. 'Capturing human motion using body-fixed sensors: Outdoor measurement and clinical applications', Computer Animation and Virtual Worlds, vol. 15, no. 2, pp. 79-94.

Ando, B., 2003, 'Electronic sensory systems for the visually impaired', IEEE Measurement Magazine, vol. 6 No. 2, pp. 62- 67.

Bamberg, S.J.M., Benbasat, A.Y., Scarborough, D.M., Krebs, D.E. and Paradiso, J.A., 2008. 'Gait analysis using a shoe-integrated wireless sensor system', IEEE Transactions on Information Technlogy in Biomedicine, July, vol. 12, no 4, pp. 413-23.

Bank, D., 2002. 'A Novel Ultrasonic Sensing System for Autonomous Mobile Systems', IEEE Sensors Journal, vol. 2, no. 6, pp.597-606.

Berg, W.P., Alessio, H.M., Mills, E.M. and Tong, C.,1997. 'Circumstances and consequences of falls in independent community-dwelling older adults', Age Ageing, Vol. 26 , No. 4, pp. 261-268.

Berns, A., Buder, U., Obermeier, E., Wolter, A. and Leder, A., 2006. 'AeroMEMS sensor array for high-resolution wall pressure measurements', Sensors and Actuators A:Physical,vol. 132,pp. 104-111.

Best, R. and Begg, R.K., 2006. 'Overview of Measurement Analysis and Gait Features', in Computational Intelligence for Movement Sciences: Neural Networks and Other Emerging Techniques, eds Begg, R.K. and Palaniswami, M., Hershey, PA, USA, pp. 1-69.

Bistue, G., Elizalde, J. G., Garcia-Alonso, S., Castano, E., Gracia, F. J. and Garcia-Alonso, A., 1997. 'A design tool for pressure microsensors based on FEM simulations', Sensors and Actuators A: Physical, vol. 62, pp. 591-594.

Bontrager, E.L.1998. 'Instrumented gait analysis systems' in Gait Analysis in the. Science of Rehabilitation, ed. De Lisa, J.A., Chapter 2. Department of Veterans Affairs, Washington, DC, USA. pp. 11-32.

Boulton, A., 2004. 'Pressure and the diabetic foot: clinical science and offloading techniques', The American Journal of Surgery, Vol. 187, No. 5, pp. S17-S24.

Bruinsma, A.J.A, 2006. Level sensor lithographic apparatus and device manufacturing method, Paris,France: European Patent Office, EP1674939A1.

Bryzek, J., Roundy, S., Bircumshaw, B., Chung, C. A. C. C., Castellino, K. A. C. K., Stetter, J. R. and Vestel, M. A. V. M., 2006, 'Marvelous MEMS', Circuits and Devices Magazine, IEEE, vol. 22, pp. 8-28. 
C. Hierold, 2003. 'Micro- and Nanosystems: Review and Outlook', in Proceedings of the 14th Micromechanics Europe Workshop (MME03), Nov. 2-4, Delft, The Netherlands, pp. 101-104.

Cardenas, M.L., Cardenas-Valencia, A. M., Dlutowski, J., Bumgarner, J. and Langebrake, L., 2007. 'A finite element method modeling approach for the development of metalsilicon nitride MEMS single-use valve arrays', J. Micromech. Microeng., vol. 17, pp 1671-1679.

Carol, M. W., Sarah, M. G. and Sharon, J. D., 1999. 'The shock attenuation characteristics of four different insoles when worn in a military boot during running and marching', Gait E Posture, vol. 9, no. 1, pp.31-37.

Carullo, A. and Parvis, M., 2001. 'An Ultrasonic Sensor for Distance Measurement in Automotive Applications', IEEE Sensors Journal, vol. 1, no. 2, pp.143-146.

Cavanagh, PR., Ulbrecht, JS. and Caputo, GM., 2000. 'New developments in the biomechanics of the diabetic foot',. Sep-Oct., Diabetes Metab Res, Rev. 16, Suppl. 1, pp. S6-S10.

Chesnin, K. J., Selby-Silverstein, L. and Besser, M. P., 2000. 'Comparison of an in-shoe pressure measurement device to a force plate: concurrent validity of center of pressure measurements', Gait \& Posture, Vol. 12, No. 2, 1 October, pp. 128-133.

Coleman, D.J., Silverman, R.H., Chabi, A., Rondeau, M.J., Shung, K.K., Cannata, J., Lincoff, H. 2004. 'High-resolution Ultrasonic imaging of the posterior segment', Ophthalmology, Vol. 111, No 7, pp. 1344-1351.

Coventor Inc.,2006. CoventorWare ${ }^{\circledR}$ 2006:Master Help, Coventor Inc., Cary, NC, USA.

Curran, S. A. and Dananberg, H. J. 2005. 'Future of Gait Analysis: A Podiatric Medical Perspective', Journal of American Podiatry Medical Association, vol. 95, no 2, pp 130142.

Elble, R.J., Thomas, S.S., Higgins, C. and Colliver, J.,1991. 'Stride-dependent changes in gait of older people', Journal of Neurology, vol. 238, no 1, pp 1-5.

Ergun, A. S., Yaralioglu, G.G., Oralkan, O. and Khuri-Yakub, B. T.,2006. 'Techniques and Applications of Capacitive Micromachined Ultrasonic Transducers', in MEMS/NEMS Handbook Techniques and Applications, ed. Cornelius T. Leondes, vol. 1, Springer, New York, USA, pp. 223-285.

Faivre, A., Dahana, M. , Parratteb B. and Monnier, G., 2004. 'Instrumented shoes for pathological gait assessment', Mechanics Research Communications, Vol. 31, no. 5, September-October, pp. 627-632.

Gefen, A.,2002. 'Biomechanical analysis of fatigue-related foot injury mechanisms in athletes and recruits during intensive marching', Medical and Biological Engineering and Computing,Vol. 40, No. 3, pp. 302-310.

Gong, S.-C. and Lee, C., 2001. 'Analysis solutions of sensitivity for pressure microsensors', IEEE Sensors Journal, Vol.1, No.4, pp. 340-344.

Grace, R,H., 1991. ‘OEM Sensors For The'90's: An Overview Of Enabling Technologies', in Proceedings of Electro International 1991, pp. 648-654.

Gueuning, F. E., Varlan, M., Eugene, C. E. and Dupuis P., 1997. 'Accurate distance measurement by an autonomous ultrasonic system combining time-of-flight and 
phase-shift methods', IEEE transactions on instrumentation and measurement, vol. 46, no 6, pp. 1236-1240.

Hamel, K. A., Okita, N., Higginson, J. S., Cavanagh, P. R., 2005. 'Foot clearance during stair descent: effects of age and illumination', Gait $\mathcal{E}$ Posture, Vol. 21, No. 2, pp. 135-140.

Hsiao H, Guan J, Weatherly M., 2002. 'Accuracy and precision of two in-shoe pressure measurement systems', Ergonomics., vol. 45, no. 8, pp 537-555.

Jia, G. and Madou, M.J., 2006. 'MEMS Fabrication', in: The MEMS Handbook: MEMS Design and Fabrication, 2nd Ed., 3, Vol. 2, ed. Gad-el-Hak, CRC Taylor and Francis, Boca Raton, Florida, USA.

Jovanov, E., Milenkovic , A., Otto , C , and de Groen , P. C, A wireless body area network of intelligent motion sensors for computer assisted physical rehabilitation, Journal of NeuroEngineering and Rehabilitation, vol. 2, 6.

Ko, H.S., Liu, C.W. and Gau, C., 2007. 'Micropressure sensor fabrication without problem of stiction for a wider range of measurement', Sensors and Actuators A: Physical, Vol. 138, No. 1, 20 July, pp. 261-267.

Kong, K. and Tomizuka, M., 2008, 'Estimation of Abnormalities in a Human Gait Using Sensor-Embedded Shoes', in Proceedings of the 2008 IEEE/ASME Int. Conf. on Adv. Intel. Mechatronics, July 2-5, Xian, China, pp. 1331-1336.

Kotzar, G., Freas, M., Abel, P., Fleischman, A., Roy, S., Zorman, C., Moran, J.M. and Melzak, J. 2002. 'Evaluation of MEMS materials of construction for implantable medical devices', Biomaterials, Vol. 23, no 13, pp.2737-2750.

Lai, D.T.H., Begg,R.K., Charry, E.,Palaniswami, M. and Hill, K., 2008. 'Measuring toe clearance using a wireless inertial sensing device', in Proceedings of International Conference on Intelligent Sensors, Sensor Networks and Information Processing, Sydney, Australia . December 15-18, pp. 375-380.

Lavery, L. A., Armstrong, D. G., Wunderlich, R. P., Tredwell, J. and Boulton, A. J.M., 2003. 'Predictive Value of Foot ressure Assessment as Part of a Population-Based Diabetes Disease Management Program', Diabetes Care, April, Vol. 26, pp.10691073.

Lee, N. K. S., Goonetilleke, R. S., Cheung, Y. S. and So, G. M. Y., 'A flexible encapsulated MEMS pressure sensor system for biomechanical applications', Microsystem Technologies, vol. 7, pp. 55-62, 2001.

Liedtke, C., Fokkenrood, S. A.W., Menger, J. T., van der Kooij, H. and Veltink, P. H., 2007, 'Evaluation of instrumented shoes for ambulatory assessment of ground reaction forces, Gait \& Posture, Vol. 26, No. 1, June, pp. 39-47.

Ling, H., Choi, P., Zheng, Y. and Lau, K., 2007. 'Extraction of mechanical properties of foot plantar tissues using ultrasound indentation associated with genetic algorithm', Journal of Materials Science: Materials in Medicine, Vol. 18, No. 8, pp. 1579-1586.

Linlin, Z., Chen, X. and Guangdi, S., 2006. Analysis for load limitation of square-shaped silicon diaphragms', Solid-State Electronics, vol. 50, pp. 1579-1583,

Luo, Berglund \& An, 1998. 'Validation of F-Scan pressure sensor system - A technical note',Journal of Rehabilitation Research and Development, Vol. . 35, No . 2, pp 186191. 
MacIsaac, D., and Hämäläinen, A., 2002, 'Physics and Technical Characteristics of Ultrasonic Sonar Systems', The Physics Teacher, vol. 40 pp. 39-46.

Mackey, J. R.,and Davis, B. L.,2006. 'Simultaneous shear and pressure sensor array for assessing pressure and shear at foot/ground interface', Journal of Biomechanics, Vol. 39, No. 15, pp. 2893-2897.

Magori,V. 1994. 'Ultrasonic sensors in air', in Proceedings of IEEE Ultrasonics Symposium 1994, pp. 471-481.

Morris, S.J., 2004, Shoe-integrated sensor system for wireless gait analysis, PhD Thesis, MIT, USA.

Mueller, M. J, 1999. 'Application of plantar pressure assessment in footwear and insert design', Journal of Orthopaedics and. Sports Physical Therapy, vol. 29, no 12, pp. 747756 .

Noble, R.A., Anthony, D., Schindel, D.W., Hutchins, D.A., Zou, L. and Sayer, M, 1995. 'The Design and Characterization of Micromachined Air-coupled Capacitance Transducer', IEEE Transactions on Ultrasonics, Ferroelectrics, and Frequency Control, vol. 42, no. 1, pp. 42-50.

Octavio, A., Martin, C.J., Martinez, O., Hernando, J., Gomez-Ullate, L. and Montero de Espinosa, F., 2007. 'A Linear CMUT Air-Coupled Array For NDE Based on MUMPS', in Proceedings of IEEE Ultrasonics Symposium, 28-31 Oct., pp. 2127-2130.

Ohya, A., Ohno,T. and Yuta, S., 1996. 'Obstacle Detectability of Ultrasonic Ranging System and Sonar Map Understanding', Robotics and Autonomous Systems, Vol.18, pp.251257.

Rodgers, M.M., 1988. 'Dynamic biomechanics of the normal foot and ankle during walking and running', Physical Therapy, vol. 68, no 12, pp. 1822-1830.

Sabatini, A. M. and Colla, V., 1998. 'A method for sonar based recognition of walking people", Robotics and Autonomous Systems', Vol. 24, pp. 117-126, 1998.

Santarmou, E., Dozza, M., Lannocca, M., Chiari, L. and Cappello, A., 2006. 'Insole pressure sensor-based audio-biofeedback for balance improvement', Gait $\mathcal{E}$ Posture, vol. 24, pp. S30-S31.

Sieh P. and Steffen M. 2006. Playing the E-Field: Capacitance Sensors in Action, Sensors, viewed 11 Dec. 2006, -

<http://www.sensorsmag.com/sensors/content/printContentPopup.jsp?id=36983 9>.

Simon, S.R., 2004. 'Quantification of human motion: gait analysis - benefits and limitations to its application to clinical problems', Journal of Biomechanics, Vol. 37, No. 12, pp. 1869-1880.

Simpson, R., LoPresti, E., Hayashi, S., Nourbakhsh, I. and Miller, D., 2004. 'The Smart Wheelchair Component System', Journal of Rehabilitation Research and Development, Vol. 41, No 3B, May/June, pp. 429 - 442.

Smith, C.V., Jr. and Schoenwald, J.S., 1984. 'A Two Tone Narrow Bandwidth Range-Rate Finding System', in Proceedings of IEEE 1984 Ultrasonics Symposium, pp. 465 - 468.

Song, K., Chen, C. and Huang, C. C., 2004. 'Design and experimental study of an ultrasonic sensor system for lateral collision avoidance at low speeds', in Proceedings of 2004 IEEE Intelligent Vehicles Symposium, 14-17 June, pp. 647 - 652. 
Svilainis, L. and Dumbrava, V., 2005. 'Design of a low noise preamplifier for ultrasonic transducer', ULTRAGARSAS, vol. 55 no.2, , pp.28-33.

Tanwar, H., Nguyen L. and Stergiou, N., 2007. 'Force Sensitive Resistor (FSR)-based Wireless Gait Analysis Device', in Proceedings of Telehealth - 2007, May 31 - June 1 ,Montreal, QC, Canada.

Turner, J. D. \& Austin, L., 2000. 'Review Article:Sensors for automotive telematics', Meas. Sci. Technol. Vol. 11 , pp. R58-R79.

Urry, S., 1999. 'Plantar pressure-measurement sensors', Measurement Science and Technology, vol. 10, pp. R16-R32.

van Schie, C. H. M., 2005. A Review of the Biomechanics of the Diabetic Foot., Lower Extremity Wounds, Vol. 4, No. 3, pp. 160-170.

Wahab, Y, Zayegh, A., and Veljanovski, R., and Begg, R.K., 2008. 'Sensitivity optimization of a foot plantar pressure micro-sensor', in Proc. 20th IEEE International Conf. on Microelectronics 2008. Sharjah, UAE, 14-17 Dec., pp 104-107.

Wahab, Y, Zayegh, A., Begg, R.K. and Veljanovski, R. , 2007b, 'CMUT For Human And Humanoid Locomotion Mesurement', in Proceedings of Int. Con. on Robotics, Vision, Information and Signal Processing 2007, Universiti Sains Malaysia, Penang, Malaysia, pp. 359-364.

Wahab, Y, Zayegh, A., Begg, R.K. and Veljanovski, R., 2007a, 'Analysis of foot to ground clearance measurement techniques for MEMS realization', in Proceedings of the IEEE International Conference on Computer and Information Technology (ICCIT 2007, Dhaka Bangladesh, pp. 1-5.

Wang, Z., Zhu, W., Miao, J., Zhu, H., Chao, C. and Tan, O. K., 2006, 'Micromachined thick film piezoelectric ultrasonic transducer array', Sensors and Actuators A: Physical, Vol. 130-131, Selected Papers from TRANSDUCERS '05 - The 13th International Conference on Solid-State Sensors, Actuators and Microsystems - Seoul, Korea, 5-9 June 2005, 14 August, pp. 485-490.

Weir, R. F. and Childress, D. S., 1997. 'A new method of characterizing gait using a Wells, L.H., 1968. 'Basic ultrasonics: 2 - The use of compression (longitudinal) waves in ultrasonic testing', Non-Destructive Testing, Vol. 1, No. 5, August, pp. 291-296.

Wheeler, J., Rohrer, B., Kholwadwala, D., Buerger, S., Givler, R., Neely, J., Hobart, C. and Galambos, P., 2006. 'In-Sole MEMS Pressure Sensing for a LowerExtremity Exoskeleton', in Proceedings of The First IEEE/RAS-EMBS International Conference on Biomedical Robotics and Biomechatronics, pp. 31-34.

Wild, S., Roglic, G., Green, R. Sicree, A. and King, H., 2004. 'Global Prevalence of Diabetes', Diabetes Care, Vol. 27, No 5, pp 1047-1053.

Winter, D.A., 1992. 'Foot trajectory in human gait: a precise and multi-factorial motor control task'. Physical Therapy, vol. 72, no 1, pp 45-56.

Wygant, I.O., Zhuang, X., Yeh, D.T., Nikoozadeh, A., Oralkan, O., Ergun, A.S., Karaman, M. and Khuri-Yakub, B.T., 2004, 'Integrated ultrasonic imaging systems based on CMUT arrays: recent progress', in Proceedings of the IEEE International Ultrasonics Symposium, vol. 1, IEEE, pp. 391-394. 
Yano, T., Tone, M., and Akira Fukumoto, A., 1987. 'Range Finding and Surface Characterization Using High Frequency Air Transducers', IEEE Transactions on Ultrasonics, Ferroelectrics, and Frequency Control, vol. UFFC 34, no. 2, pp. 232-236.

Zamali, M.S.B. and Talghader, J.J., 2006, 'Stress-mapping sensors for high-power adaptive micro-optics', Applied Optics, Vol. 45, No. 7, March, pp1619-1624. 


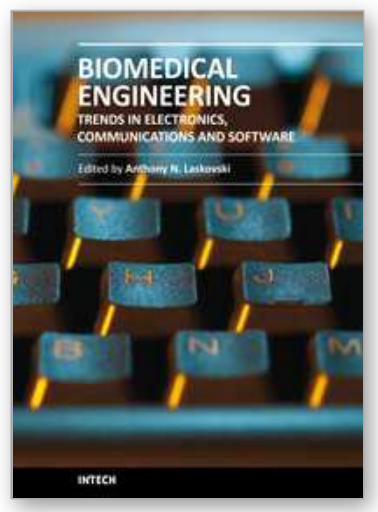

\author{
Biomedical Engineering, Trends in Electronics, Communications \\ and Software \\ Edited by Mr Anthony Laskovski
}

ISBN 978-953-307-475-7

Hard cover, 736 pages

Publisher InTech

Published online 08, January, 2011

Published in print edition January, 2011

Rapid technological developments in the last century have brought the field of biomedical engineering into a totally new realm. Breakthroughs in materials science, imaging, electronics and, more recently, the information age have improved our understanding of the human body. As a result, the field of biomedical engineering is thriving, with innovations that aim to improve the quality and reduce the cost of medical care. This book is the first in a series of three that will present recent trends in biomedical engineering, with a particular focus on applications in electronics and communications. More specifically: wireless monitoring, sensors, medical imaging and the management of medical information are covered, among other subjects.

\title{
How to reference
}

In order to correctly reference this scholarly work, feel free to copy and paste the following:

Yufridin Wahab and Norantanum Abu Bakar (2011). MEMS Biomedical Sensor for Gait Analysis, Biomedical Engineering, Trends in Electronics, Communications and Software, Mr Anthony Laskovski (Ed.), ISBN: 978953-307-475-7, InTech, Available from: http://www.intechopen.com/books/biomedical-engineering-trends-inelectronics-communications-and-software/mems-biomedical-sensor-for-gait-analysis

\section{INTECH}

open science | open minds

\section{InTech Europe}

University Campus STeP Ri

Slavka Krautzeka 83/A

51000 Rijeka, Croatia

Phone: +385 (51) 770447

Fax: +385 (51) 686166

www.intechopen.com

\section{InTech China}

Unit 405, Office Block, Hotel Equatorial Shanghai

No.65, Yan An Road (West), Shanghai, 200040, China

中国上海市延安西路65号上海国际贵都大饭店办公楼405单元

Phone: +86-21-62489820

Fax: +86-21-62489821 
(C) 2011 The Author(s). Licensee IntechOpen. This chapter is distributed under the terms of the Creative Commons Attribution-NonCommercialShareAlike-3.0 License, which permits use, distribution and reproduction for non-commercial purposes, provided the original is properly cited and derivative works building on this content are distributed under the same license. 